Original Research Paper

\title{
How Can the Public Monitor Monetary Policy?
}

\author{
Takashi Senda \\ Department of Economics, Graduate Schools of Social Sciences, \\ Hiroshima University, 1-2-1 Kagamiyama, Higashihiroshima, Japan
}

\section{Article history}

Received: 30-06-2017

Revised: 09-06-2017

Accepted: 04-07-2017

Email: tsenda@hiroshima-u.ac.jp

\begin{abstract}
On August 11, 2000, the Bank of Japan made one of the most controversial decisions in the history of monetary policy when it ended its zero-interest-rate policy and increased the overnight rate to $0.25 \%$. This paper aims to examine whether or not this decision to terminate the zero-interest-rate policy was premature. In this study, I argue that this decision by the Bank of Japan to tighten monetary policy in 2000 was unreasonable as there still remained a great deal of slack in the economy and inflation was not far from its target. On reading the minutes of the Monetary Policy Meeting of August 11, 2000, I observe that some arguments for tightening monetary policy seem to confuse rates of change and levels.
\end{abstract}

Keywords: Monetary Policy, Forecast Targeting, Inflation Targeting, Bank of Japan, JEL Codes: E52, E58

\section{Introduction}

One of the most controversial decisions in the history of monetary policy was made by the Bank of Japan (BOJ) on August 11, 2000 when it terminated its zerointerest-rate policy and raised the overnight rate to $0.25 \%$. At a press conference immediately following the Monetary Policy Meeting, the then Governor of the BOJ, Masaru Hayami, defended the BOJ's decision by stating that the Japanese economy had grown at an annual rate of about $10 \%$ in the first quarter of 2000 and the growth rate of the current fiscal year was expected to be much higher than that of the previous fiscal year $(0.5 \%)$.

However, the BOJ faced some harsh criticism over this decision, particularly from economists outside Japan. For example, Krugman (2000) wrote, "I would not be surprised if future economic historians look back at Friday's move as the beginning of the end for an era and not just in Japan." More recently, Yellen (2015) stated:

The experience of Japan over the past 20 years and Sweden more recently, demonstrates that a tightening of policy when the equilibrium real rate remains low can result in appreciable economic costs, delaying the attainment of a central bank's price stability objective

This paper aims to examine whether or not this decision to terminate the zero-interest-rate policy was premature. Svensson's (2011) study, which compared monetary policy decisions in Sweden and the United States during 2010-2011, is used to evaluate the BOJ's decision. Svensson used Qvigstad's (2005) criterion to determine whether an interest rate path "looks good." I also examine the minutes of the Monetary Policy Meeting to investigate the process used to reach the conclusion that the BOJ would exit its zero-interestrate policy.

In this study, I argue that the BOJ's decision to tighten monetary policy in 2000 was unreasonable as there still remained a large amount of slack in the economy and inflation was not far from its target. By reading the minutes of the Monetary Policy Meeting of August 11, 2000, I find that some arguments for tightening monetary policy seem to confuse rates of change and levels.

The paper is organized as follows. Section II examines what the BOJ officials knew when they decided to lift the zero-interest-rate policy. Section III discusses inflation and unemployment projections that were available at the meeting when the decision to raise interest rates was taken. Section IV attempts to identify specific periods when changing policy rates were said to "look good" and compares them with actual policy changes. Section V scrutinizes the minutes of the Monetary Policy Meeting when the BOJ decided to change its policy rates and reviews the process of discussion that led to the termination of the zero-interestrate policy. Section VI closes with a concluding remark. 


\section{What the BOJ Knew At the Monetary Policy Meeting on August 11, 2000}

On August 11, 2000, the BOJ decided to raise its policy rate and end the zero-interest-rate policy that had been in effect for the last 18 months. To understand this decision, it is necessary to determine what information was available to the Policy Board members at the time of the Monetary Policy Meeting.

In this section, I use the latest forecasts published by the International Monetary Fund (IMF, April 2000) and the Organization for Economic Co-operation and Development (OECD, June 2000) as of August 11, 2000. These forecasts were publicly available at the time of the Monetary Policy Meeting.

Figure 1a depicts the IMF estimates of GDP through 1999 while Fig. $1 \mathrm{~b}$ depicts the OECD estimates. For the IMF estimates, GDP in 1999 was $2.2 \%$ less than the 1997 peak, 4.6\% less than the trend at the time and slightly less than the 1996 level. For the OECD estimates, similarly, GDP in 1999 was $2.3 \%$ less than the 1997 peak, a full $4 \%$ less than the trend and slightly less than the 1996 level.

Furthermore, as observed in Fig. 2, the unemployment rate, a more reliable measure of resource utilization, was $4.68 \%$ in 1999 , the highest since World War II. CPI inflation was $-0.32 \%$ in 1999 . At the time, the BOJ aimed to achieve price stability and intended to maintain interest rates at zero "until deflationary concerns are dispelled." According to monthly and quarterly government data, the unemployment rate in June 2000 was $4.7 \%$ while the year-on-year rate of change in the CPI was $-0.58 \%$ and inflation measured according to the growth rate of the GDP deflator from the previous quarter to the first quarter of 2000 was $-2 \%$ (annualized rate). Thus, it is difficult to justify monetary policy tightening when actual output is far below its potential and inflation is not far from its target.

After contracting for two consecutive quarters, the growth rate of real GDP from the previous quarter to the first quarter of 2000 was $10 \%$ (annualized rate). Potential GDP was expected to grow at a rate of $1-2 \%$. Actual GDP growth was higher than growth in potential GDP; however, to close the gap between actual and potential GDP, above-normal growth was necessary for a certain period of time. Tightening monetary policy to reduce growth might prevent the economy from recovering, thus prolonging the recession.

\section{Forecast Targeting}

As monetary policy influences future inflation with a control lag of 1.5-2 years, the inflation forecast is used as an intermediate target (Svensson, 1997). The data used in this study have been sourced from IMF and OECD forecasts for inflation, the GDP gap and unemployment.

Figure 3 is constructed from the IMF World Economic Outlook for May 2000 and the OECD
Economic Outlook for June 2000, which were available for the August 11 Monetary Policy Meeting. The series through 1999 are outcomes and those beyond 2000 are forecasts by international think tanks.

The negative GDP gap, which is not indicated here, was projected to persist in 2000 and 2001. In Fig. 3, inflation is measured by the consumer price index for the IMF and the GDP deflator for the OECD. In 1997, inflation temporarily increased due to the consumption tax hike from 3 to $5 \%$. In those days, the argument indicated that the central bank should have maintained its monetary easing policy until deflationary concerns could be dispelled. This paper assumes that the BOJ targeted headline inflation at $0 \%$ in 2000 . As the figure shows, inflation was negative in 1999 and the IMF forecasted that the inflation would be close to $0 \%$ for 2000 and a little less than $1 \%$ for 2001 . The OECD's forecast for inflation was negative for 1999 and 2000 and approximately zero for 2001 . Therefore, both institutions were forecasting the negative GDP gap and that inflation would be close to zero and thus these forecasts indicated that there was no convincing reason to raise interest rates. Furthermore, the IMF's forecast for inflation showed a steady recovery, although it is unclear why inflation rose to such a level despite a large negative output gap.

Figure 4 shows the realized and OECD forecast unemployment rates available for the August 11 Monetary Policy Meeting. The unemployment rate reached $4.68 \%$ in 1999 and was expected to worsen over the next two years. The figure also depicts the government's estimate of the structural unemployment rate. In the Annual Report on the Japanese Economy (Cabinet Office, June 2000), actual unemployment was divided into two types: Structural and cyclical. The latest estimate of the structural unemployment rate was $3.75 \%$, which I assume here to be the sustainable unemployment rate as of the August meeting. The forecast unemployment rate was about $1 \%$ higher than the sustainable unemployment rate. Furthermore, the unemployment rate and the GDP suggest that forecast resource utilization was too low.

In such a situation, the central bank should have eased monetary policy, if possible. A monetary easing policy would have shifted inflation and the inflation forecast upward and ensured that deflation was overcome. Such a policy would have also reduced the negative output gap and shifted the unemployment rate closer to the sustainable level. However, one may argue that it was difficult for the BOJ to implement additional monetary easing measures because short-term nominal interest rates were already hitting the zero lower bound. Instead of launching aggressive monetary easing or keeping rates at zero, the Policy Board surprisingly decided to raise rates at the August 11 Monetary Policy Meeting. Chairman Masaru Hayami's proposal to lift the zero-interest-rate policy was approved by a majority; only two members of the Policy Board dissented. 
Takashi Senda / American Journal of Economics and Business Administration 2017, 9 (2): 38.46

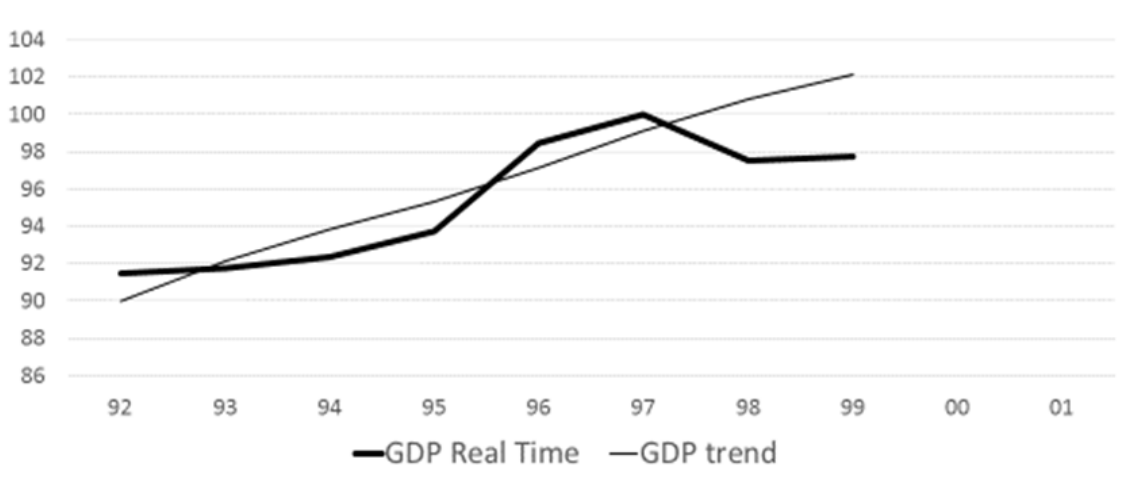

(a)

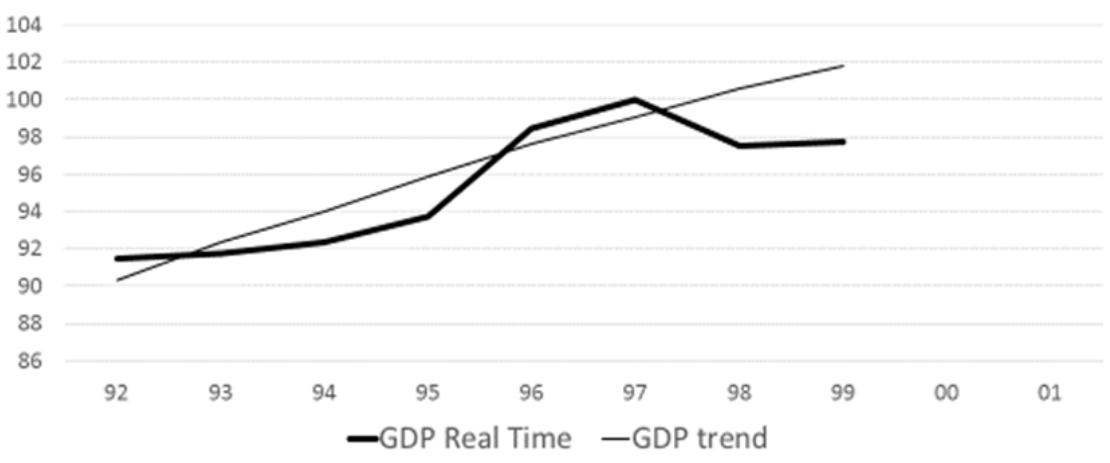

(b)

Fig. 1. GDP real time and GDP trend, (a) IMF (b) OECD

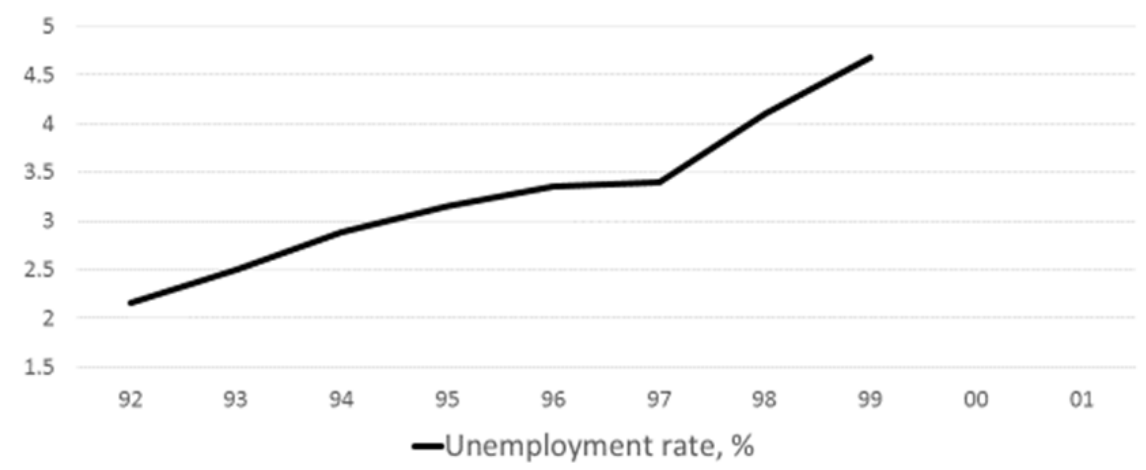

Fig. 2. Unemployment rate

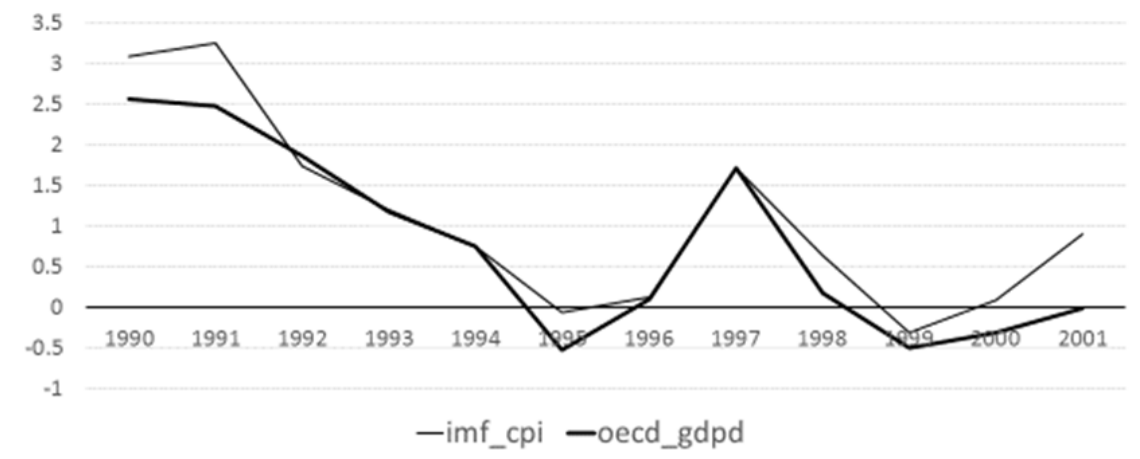

Fig. 3. Inflation, realized and forecast 
At the same meeting, prior to the vote on the Chairman's proposal, the government requested a postponement of the vote citing the reason that it was premature to terminate the zero-interest-rate policy given the economic situation and recent developments in financial markets. The government's request to postpone the vote on the Chairman's policy proposal was put to the vote and defeated by majority.

\section{The Situation one Year Later}

The discussion so far suggests that in the summer of 2000, the BOJ should have leaned more toward monetary easing rather than tightening because forecast unemployment was too high as compared with the sustainable unemployment rate. That is, a more expansionary policy regarding the ex ante policy evaluation was appropriate, if possible.

Inflation shocks could have subsequently hit the Japanese economy and the policy tightening in August 2000 could have turned out to be right ex post. However, ex ante policy evaluation is more important than ex post evaluation because the latter largely means assessing whether policymakers were lucky or unlucky. Nonetheless, it is still interesting to determine whether the tightening was right ex post.

Figure 5 shows realized and forecast CPI inflation from the IMF World Economic Outlook for May 2001 and the OECD Economic Outlook for June 2001. Both think tanks forecast negative inflation from 2000 to 2002, except in 2002 for the IMF estimates. Figure 6 shows GDP estimates and forecasts by the IMF, Fig. 7 by the OECD and Fig. 8 presents the unemployment rate and the Non-Accelerating Inflation Rate of Unemployment (NAIRU) according to OECD estimates. These figures indicate a substantial slack in the economy during 2000-2002. A year later, inflation and the inflation forecast and various resource utilization measures were still too low, thus suggesting that the tightening in 2000 was wrong even in the ex post evaluation.

\section{Monitoring Monetary Policy}

Changing the monetary policy stance has always attracted attention, as is clear from the case with the August 2000 meeting. Is the decision taken in the August 2000 meeting more unique than other similar decisions or is it very common? Using the IMF and OECD forecasts, I conduct ex ante assessments of monetary policy changes.

Figure 9 shows the OECD forecasts for the Japanese economy. The sample period considered is from June 1989 to November 2015. Each forecast is computed by taking an average of forecasts over the forecast horizon. The forecast horizon is either two or three years, depending on the available data. In Fig. 9a, for example, the forecast value for year $t$ is either an average of inflation forecasts in year $t$ and year $t+1$ or an average of inflation forecasts in year $t$, year $t+1$ and year $t+2$. When the data are published in the first half of the year (January-June), inflation forecasts $\pi_{t}^{e}$ and $\pi_{t+1}^{e}$ are available. Thus, the forecast value for year $t, \Pi_{t}^{e}$, is obtained from:

$$
\Pi_{t}^{e}=\frac{\pi_{t}^{e}+\pi_{t+1}^{e}}{2}
$$

On the other hand, when the data are published in the second half of the year (July-December), inflation forecasts $\pi_{t}^{e}, \pi_{t+1}^{e}$ and $\pi_{t+2}^{e}$ are available and the forecast value is calculated by:

$$
\Pi_{t}^{e}=\frac{\pi_{t}^{e}+\pi_{t+1}^{e}+\pi_{t+2}^{e}}{3}
$$

I assume that the BOJ's inflation target is $0 \%$ before February 2006, 1\% from March 2006 to March 2013 and $2 \%$ after April 2013. When the BOJ adapted the zero-interest-rate policy, it stated that the policy would continue to be in effect until the deflationary concern was dispelled. In March 2001, the BOJ introduced Quantitative Easing (QE) and announced that it would continue QE until the annual rate of change in the Consumer Price Index (CPI, excluding fresh food) registered a rate of $0 \%$ or above in a stable manner. The QE policy ended in March 2006 and on March 10, 2006, the BOJ released "The Bank's thinking on Price Stability," stating that "most Board members' median figures fell on both sides of $1 \%$." Hence, I assume that the inflation target is $0 \%$ before February 2006 and 1\% after March 2006. Finally, on April 4, 2013, the BOJ adopted a 2\% inflation target. The dotted lines in Fig. 9a represent changes in the inflation target rate.

Figure 9a indicates that the inflation forecast was above the target for the periods from June 1989 to December 1994 and December 1996 to June 1998 and for December 2004, December 2005 and May 2014 while it was below the target for the rest of the sample. Figure $9 \mathrm{~b}$ shows that the output gap forecast was positive from June 1989 to December 1992, for June 2004 and from December 2005 to June 2008, June 2013 to May 2014 and June 2015 to November 2015 while it was negative for the rest of the sample. For the unemployment rate, the sample period is shorter (June 2001 to November 2015). Figure 9c depicts that the unemployment forecast was below the NAIRU for the periods from June 2006 to June 2008 and June 2013 to November 2015 while it was above the NAIRU for the rest of the sample. 


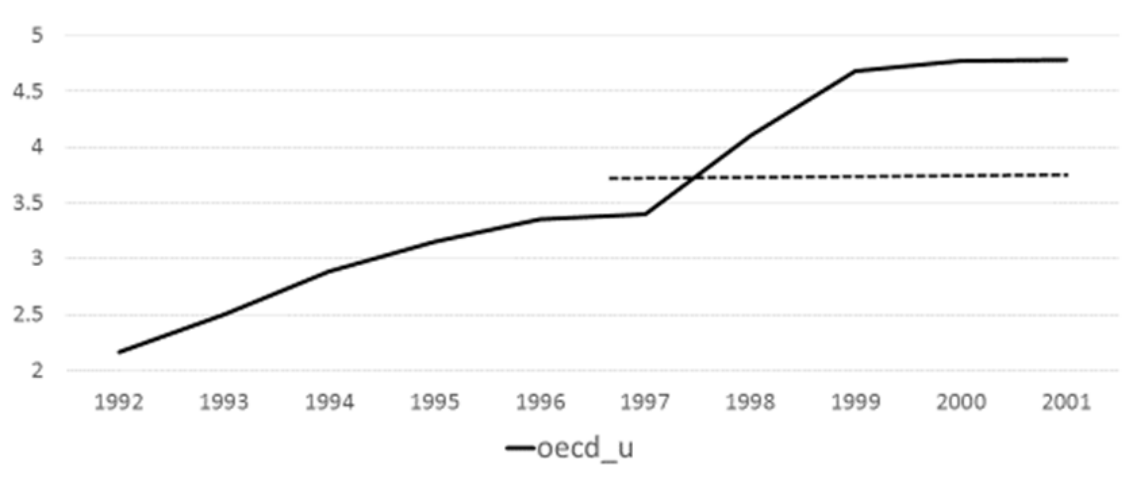

Fig. 4. Unemployment rate, realized and forecast

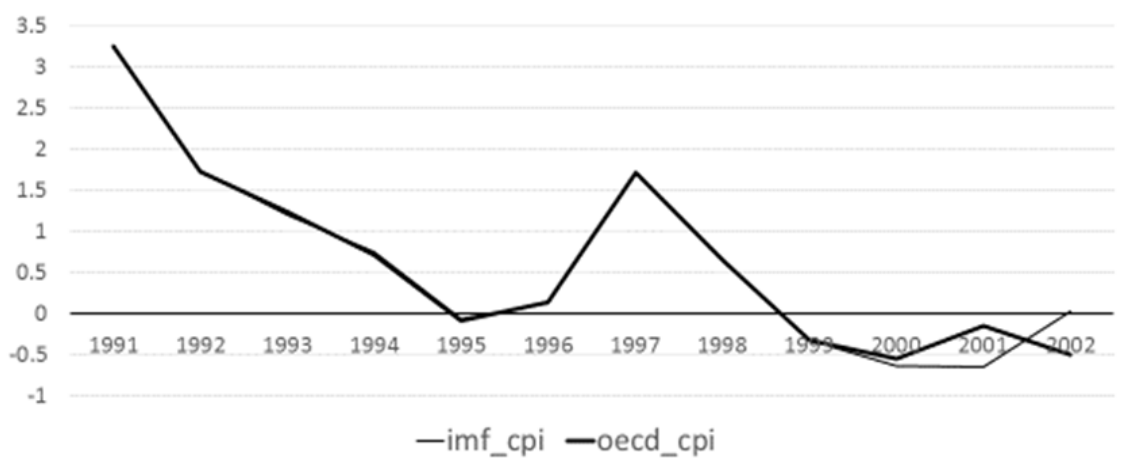

Fig. 5. Inflation, realized and forecast

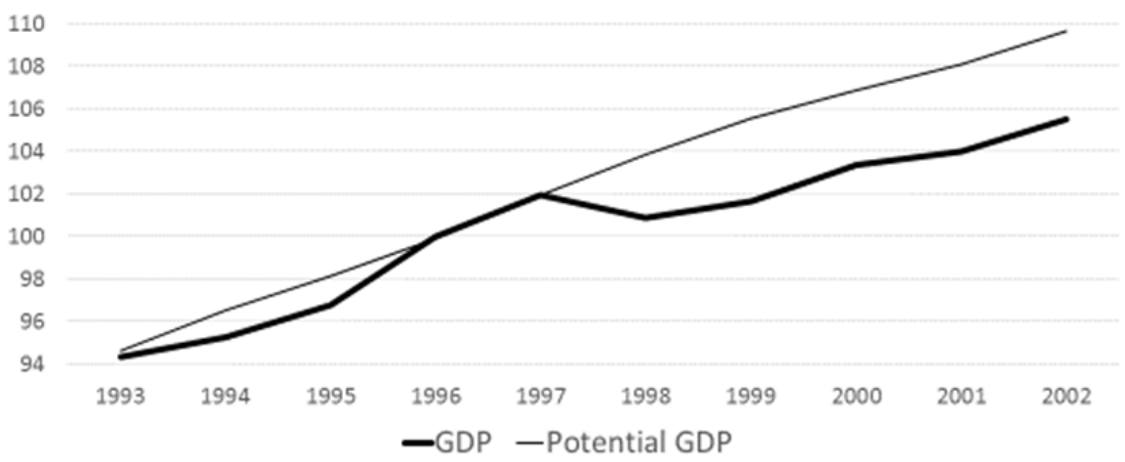

Fig. 6. GDP, realized and forecast and potential GDP, IMF

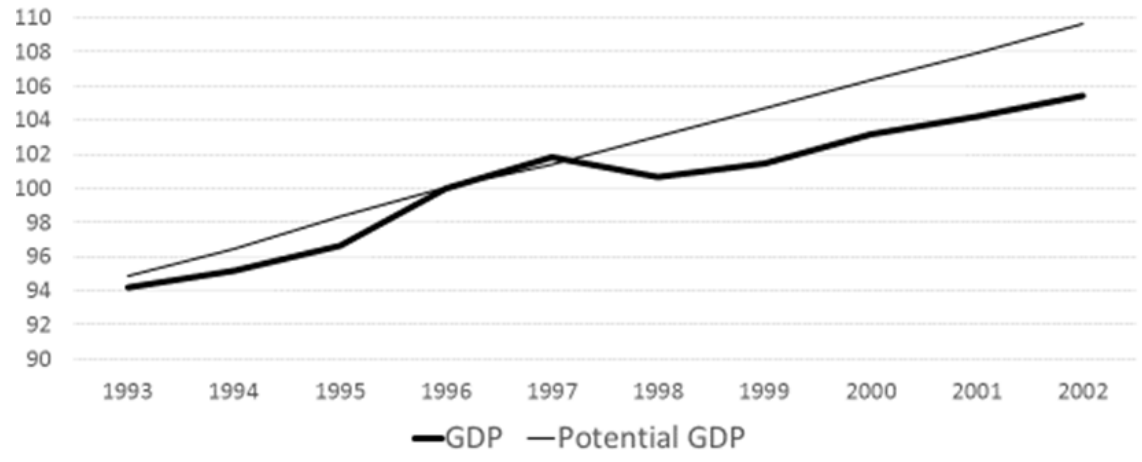

Fig. 7. GDP, realized and forecast and potential GDP, OECD 


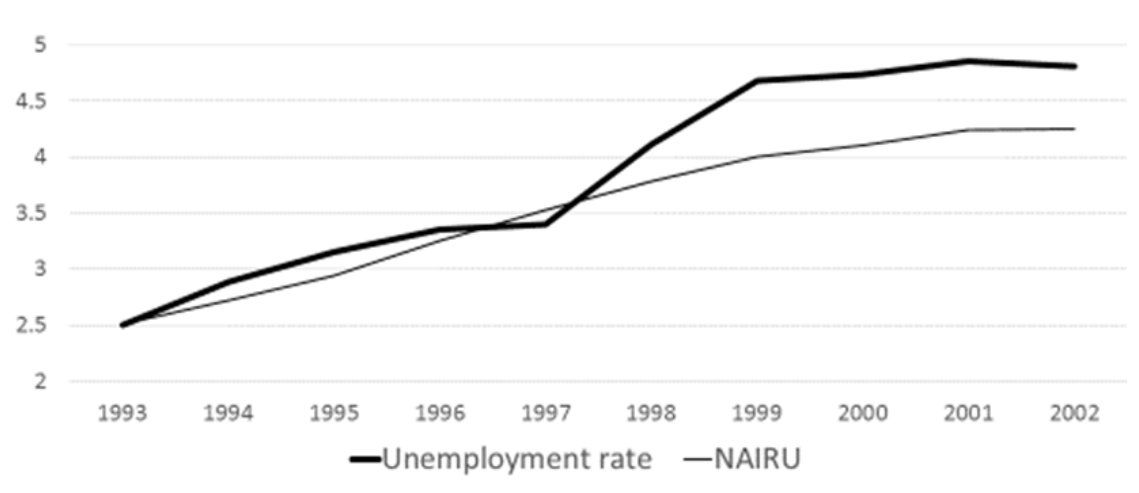

Fig. 8. Unemployment rate, realized and forecast and the NAIRU
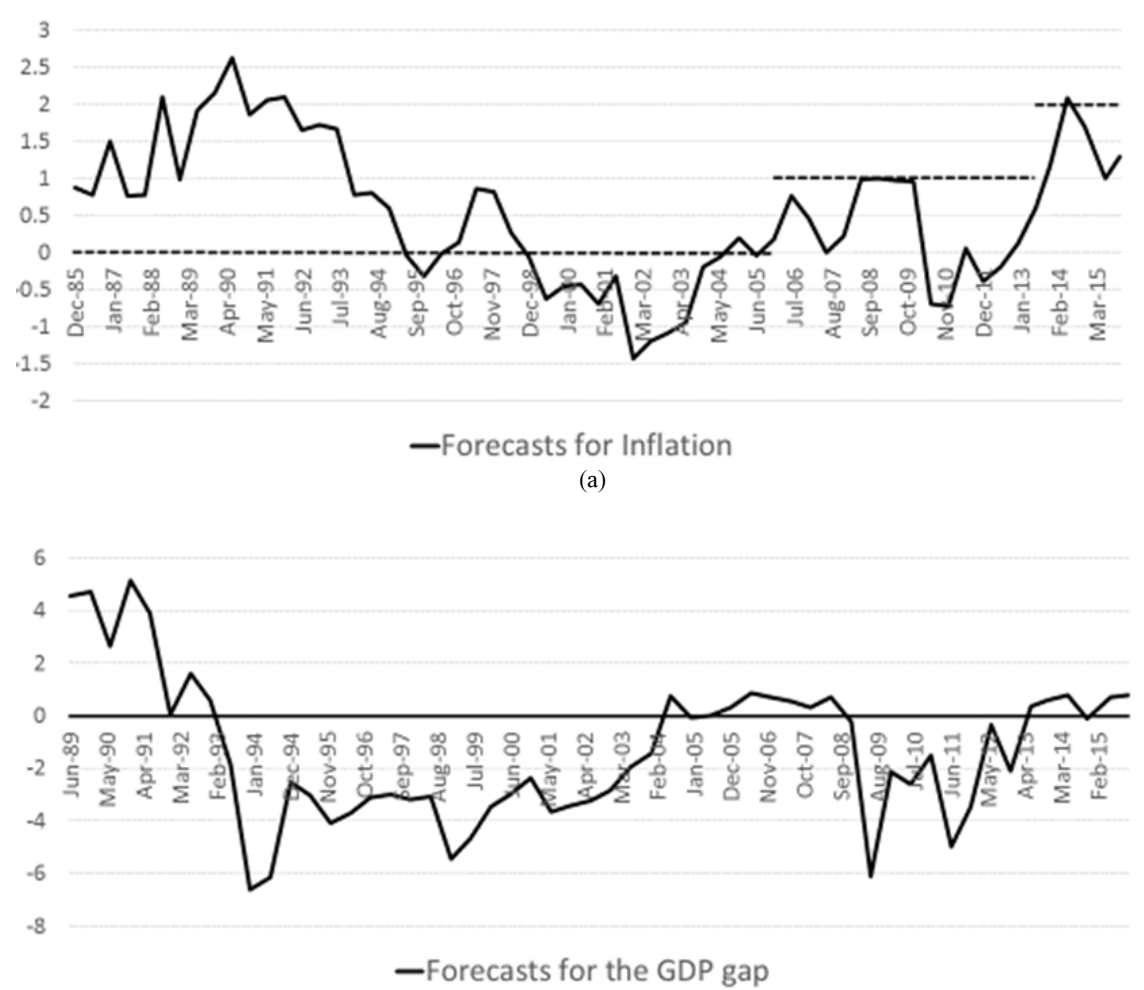

(b)

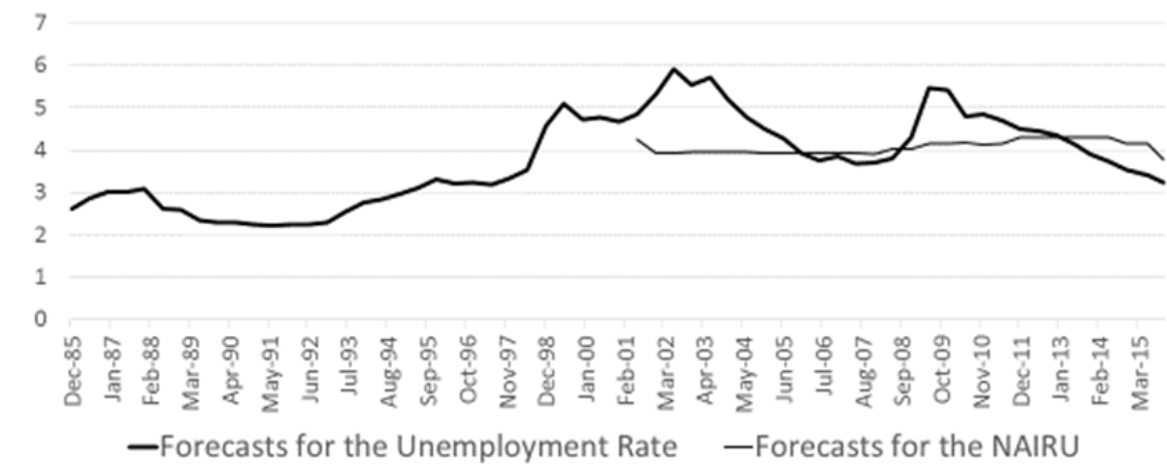

(c)

Fig. 9. (a) Forecasts for inflation, OECD (b) GDP gap, OECD (c) Unemployment rate and the NAIRU, OECD 
As in Svensson (2011), this study employs Qvigstad's (2005) criterion to choose a policy rate path for which the inflation and unemployment (or the output gap) forecasts "look good." The criterion can be operationalized as follows. The inflation gap and output gap forecasts should not be positive or negative simultaneously. If both gaps are positive, for example, then a tighter policy would be preferable since it would stabilize both inflation and output.

When applying the criterion to my sample, I use the forecasts of two gaps (inflation and output) before May 2001 and the forecasts of three gaps (inflation, output and unemployment) after June 2001. For the period after June 2001, I assume that the policy rate path will be revised only if all three gaps meet the criterion.

The Qvigstad criterion and the OECD forecasts enable us to determine that it was appropriate for the central bank to raise interest rates from June 1989 to December 1992 and for May 2014 and to lower rates from June 1995 to June 1996, December 1998 to December 2003, for June 2005 and from December 2008 to December 2012. Interest rates did not require modifications for the rest of the sample.

Figure 10 shows the inflation and output forecasts by IMF. The sample period is from April 1999 to October 2015 and is thus shorter than the OECD forecasts. Similar to the OECD forecasts, the forecast horizon is either two or three years. In Fig. 10a, for example, the forecast value for year $t$ is either an average of inflation forecasts in year $t$ and year $t+1$ or an average of inflation forecasts in year $t$, year $t+1$ and year $t+2$. Figure 10a indicates that the inflation forecast was above the target from April 2000 to September 2000, April 2008 to October 2008 and April 2013 to October 2014 while it was below the target for the rest of the sample. Figure 10b shows that the output gap forecast was positive for April 2006 and April 2007 while it was negative for the rest of the sample.

The Qvigstad criterion indicates that the BOJ did not have a chance to raise interest rates for the IMF's sample period (April 1999 to October 2015). Interest rates should have been lowered for the periods from April 1999 to September 1999, April 2001 to September 2005, September 2006, for October 2007, from April 2009 to October 2012 and April 2015 to October 2015 and left unchanged for the rest of the sample.

After the collapse of the bubble economy in 1993, almost all monetary policy decisions by the BOJ were either expansionary or maintained unchanged, which is implied by both the Qvigstad criterion and the actual conduct of monetary policy; however, there were five exceptions. Four of these were the actual tightening of monetary policy (August 2000, March 2006, July 2006 and February 2007) and the fifth was the Qvigstad's criterion recommendation to tighten its policy (October 2014). Table 1 shows that in three of the four periods of monetary policy tightening, one of the two forecasts (OECD or IMF) indicated taking further easing steps and none of them recommended tightening a policy. For example, in the case of the monetary policy tightening in August 2000, the Qvigstad criterion indicated further easing for OECD forecasts and no policy change for IMF forecasts. In contrast, the BOJ implemented additional expansion measures on October 31, 2014 and the criterion with OECD forecasts recommended policy tightening. This October 2014 policy change was decided in the midst of aggressive monetary and fiscal policies dubbed "Abenomics" for Prime Minister Shinzo Abe, who had taken the initiative since December 26, 2012. The Governor of the BOJ, Mr. Haruhiko Kuroda, was nominated at the beginning of Abenomics.

The Qvigstad criterion results suggested that since Governor Kuroda assumed office, the BOJ's monetary policy stance had shifted from contractionary to expansionary. The suspension of the zero-interest-rate policy in August 2000 may have thus reflected the contractionary monetary policy stance before Governor Kuroda.

\section{Minutes of the August 2000 Meeting}

Figure 11, which shows the GDP growth rate, gives the impression that the Japanese economy underwent a steady recovery. In the August 2000 meeting, only one of the members of the Policy Board was a professional academic, Prof. Kazuo Ueda (The University of Tokyo). According to the minutes, Prof. Ueda pointed out that one needs to understand the difference between the size of the GDP gap and the change in the GDP gap. Furthermore, he observed that the GDP gap remained quite large, although it had declined somewhat. Therefore, he said that he was not completely confident that the economy had reached a stage where deflationary concern had been dispelled. Deputy Governor Yamaguchi responded that the change as well as the size of the GDP gap could have a major effect on inflation. However, the Deputy Governor's assertion was still no better than conjecture.

It is crucial to understand the difference between rates of change and levels. Unfortunately, this difference was not discussed in further detail at the meeting; as Chairman Hayami stated: "I presume that it is a theoretical and academic argument, but honestly I don't understand the difference." 


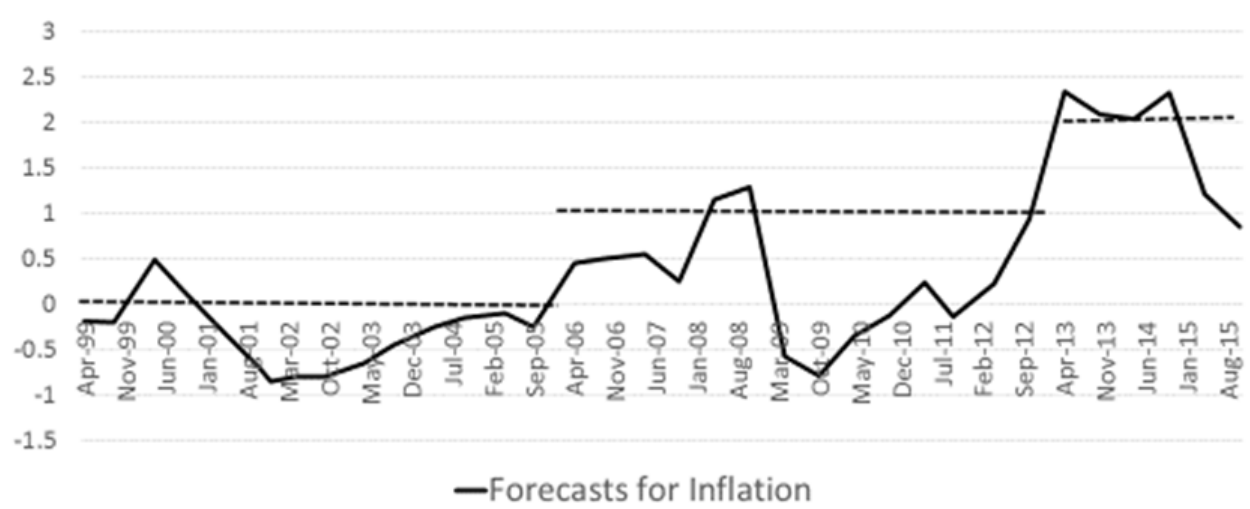

(a)

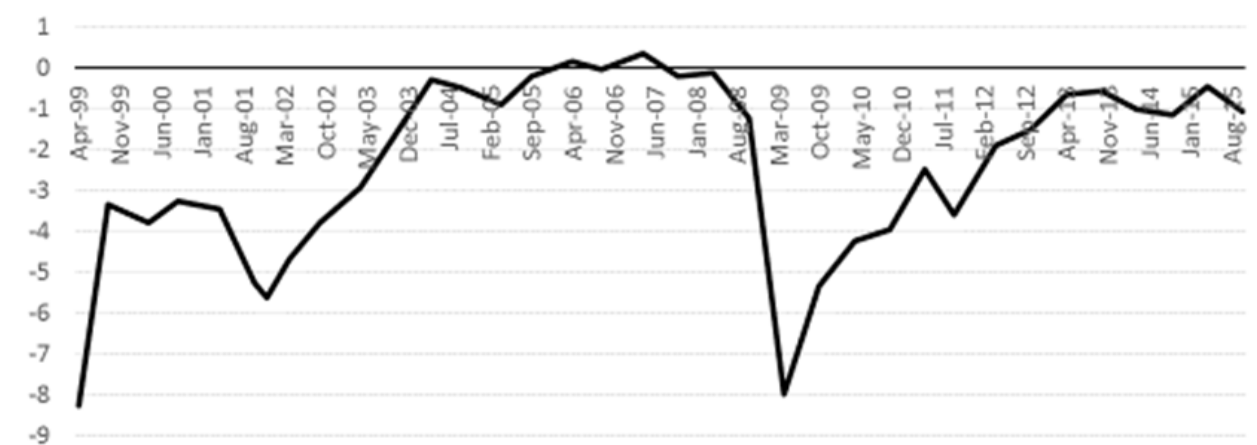

-Forecasts for the GDP gap

(b)

Fig. 10. (a) Forecasts for inflation, IMF (b) GDP gap, IMF

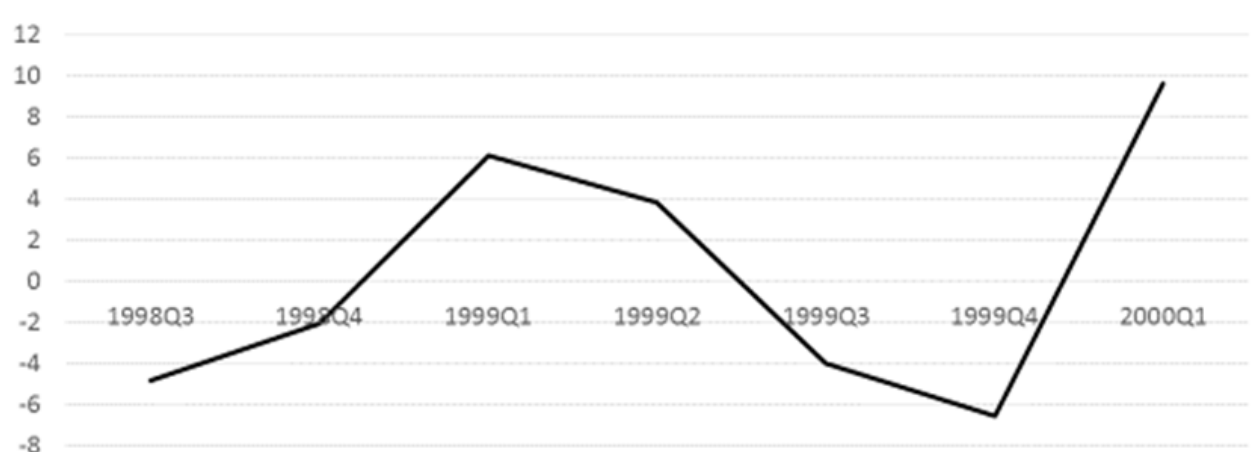

\section{—GDP Growth}

Fig. 11. GDP growth

Table 1. Recommendations base on the qvigstad criterion and actual policies

\begin{tabular}{|c|c|c|c|}
\hline & \multicolumn{3}{|c|}{ Recommendation } \\
\hline & OECD & IMF & Actual policy \\
\hline August 2000 & Expansionary & - & Contractionary \\
\hline March 2006 & - & Expansionary & Contractionary \\
\hline July 2006 & - & - & Contractionary \\
\hline February 2007 & - & Expansionary & Contractionary \\
\hline October 2014 & Contractionary & - & Expansionary \\
\hline
\end{tabular}




\section{Conclusion}

In August 2000, there remained a large amount of slack in the Japanese economy and inflation was not far from its target. I applied Svensson's framework to this situation and found that the August 2000 inflation and unemployment forecasts indicated that a more expansionary monetary policy, if possible, was appropriate in the case of Japan.

Why did the BOJ then decide to suspend the zerointerest-rate policy? As seen from my paper, it appears that the Policy Board members emphasized the change in the GDP gap rather than its level at their August 11 Monetary Policy Meeting. Therefore, the confusion between growth rates and levels probably played a role in the premature tightening of Japan's monetary policy.

\section{Acknowledgment}

The author is grateful for comments from $\mathrm{Fu}$-Sheng Hung, Harumichi Kawaguchi, Ian James Bisset and the participants at the 2016 International Forum: Public Affairs, Social Science and Economics. The author would like to thank Enago (www.enago.jp) for the English language review.

\section{Ethics}

This article is original and contains unpublished material. The corresponding author confirms that all of the other authors have read and approved the manuscript and no ethical issues involved.

\section{References}

Krugman, P., 2000. Reckonings End of the ZIRP. 1st Edn., New York Times.

Qvigstad, J.F., 2005. When does an interest rate "Look good"? Criteria for an appropriate future interest rate path---a practician's approach. Norges Bank Staff Memo no. 5/06, Oslo.

Svensson, L.E.O., 1997. Inflation forecast targeting: implementing and monitoring inflation targeting. Eur. Economic Rev., 41: 1111-46.

Svensson, L.E.O., 2011. Practical monetary policy: Examples from Sweden and the United States. Brookings Papers Economic.

Yellen, J.L., 2015. Normalizing monetary policy: Prospects and perspectives, a speech at the "The new normal monetary policy. Proceedings of the a Research Conference Sponsored by the Federal Reserve Bank, (FRB' 15), San Francisco, California. 